\title{
ANÁLISE DE ESTABILIDADE GLOBAL EM EDIFÍCIOS ALTOS
}

\section{Global stability analysis at tall buildings}

\author{
João Fernando Martins Paixão', Elcio Cassimiro Alves²
}

Recebido em 07 de fevereiro de 2016; recebido para revisão em 09 de maio de 2016; aceito em 13 de julho de 2016; disponivel on-line em 31 de agosto de 2016.

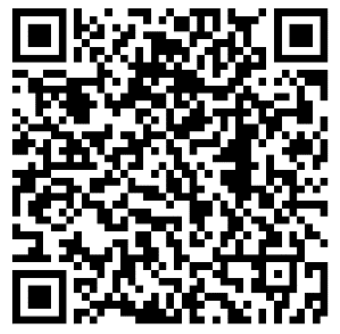

\section{PALAVRAS CHAVE:}

Análise de 2ao ordem;

Estabilidade global;

Gama Z;

Laje nervurada;

P-Delta.

\section{KEYWORDS:}

Analysus of $2^{\text {nd }}$ order; Global stability; Waffle slabs; Gama Z; P-Delta.

\section{* Contato com os autores:}

1 e-mail: joaofernando.paixao@hotmail.com (J. F. M. Paixão)

Engenheira Civil, Cursando Especialização em Cálculo Estrutural e Fundações, Universidade Federal do Espírito Santo.

2e-mail: elcio.calves1@gmail.com (E. C. Alves)

Professor Doutor do Curso de Engenharia Civil da Universidade Federal do Espírito Santo.
RESUMO: O projeto de edifícios esbeltos em concreto armado normalmente tem como principal desafio a busca por uma solução estrutural que viabilize sua estabilização horizontal, sem comprometer a segurança, nem os aspectos arquitetônicos ou a economia. Para formar o sistema de contraventamento desses edifícios, normalmente têm-se disponíveis a associação de vigas e pilares formando pórticos, ou a adoção de núcleos rígidos quando a estrutura de tais edifícios exige grande rigidez frente a ações horizontais. Neste trabalho é apresentado o estudo da estabilidade de uma edificação em concreto armado composta por laje nervurada, com ordem de esbeltez de um para quatro para três tipologias de sistemas de contraventamento: pórticos, núcleos rígidos em formato ("U" e pilar-parede). Em cada sistema, foram considerados dois diferentes tipos de ligações (rígidas e semi-rígidas) para avaliar não só a participação das vigas no contraventamento da estrutura como também, a influência de tais modelos e critérios nos deslocamentos laterais e na estabilidade global da edificação, a partir do parâmetro de instabilidade ?z previsto na norma brasileira NBR 6118 (ABNT, 2014). Para as modelagens foi utilizado o programa comercial Altoqi Eberick V9, que considera as premissas e as prescrições de dimensionamento de estruturas de concreto previstas nas normas brasileiras. Os valores encontrados pelo Software foram analisados e reforçam a importância da utilização de Pilar -Parede ou núcleos rígidos em formato " $U$ " para edifícios altos em concreto armado.

ABSTRACT: The Project of slender buildings in reinforced concret, normally has as main challenge the search for a lasting solution that allow its horizontal stabilization, without compromising the safety, neither the architectural aspects or the economy. To form the bracing system of these buildings, normally has been available the association of beams and pillars forming the frameworks, or the adoption of rigid cores when the structure of these buildings requires great rigidity against horizontal actions. In this research aimed to study the overall stability of a building in reinforced concrete consisting of waffle slab, with slenderness approximately one to four, for three types of bracing systems, frameworks and rigid core into two types of format (" $U$ " and pillars in which the lengths are signifi cantly larger than their widths). In each system were considered two different types of connections ( rigid and semi-rigid) to evaluate not only the participation of the beams in the bracing structure, even as the influence of such models and criteria in the lateral displacement and the overall stability of the building, using instability parameter $\gamma z$ fixed on Brazilian standard NBR 6118 (ABNT, 2014). For the modeling, was used the commercial software Altoqi Eberick V9, which considers the assumptions and the sizing requirements of concrete structures described in Brazilian standards. The values that were found by the software, they were analysed, and reinforce the importance of using pillars in which the lengths are signifi cantly larger than their widths or rigid core " $U$ " for tall buildings in reinforced concrete. 


\section{INTRODUÇÃO}

Com o avanço da tecnologia no desenvolvimento de softwares para projetos estruturais bem como o crescente aumento da densidade populacional ligada a uma necessidade contínua de maior urbanização nas cidades e com melhor aproveitamento de espaços, fez com que ocorresse um intenso processo de verticalização das edificações, construindo-se edifícios mais altos e mais esbeltos.

Sabe-se que em estruturas dessa magnitude a ação do vento provoca grandes efeitos, produzindo esforços adicionais quando aplicados simultaneamente com as demais ações atuantes na estrutura. Sendo assim, a avaliação da estabilidade global é um dos mais importantes fatores para a concepção estrutural de um edifício, pois ela visa garantir a segurança da estrutura mediante a perda de sua capacidade resistente causada pelo aumento das deformações em decorrência das ações.

Tradicionalmente, as estruturas de concreto armado construídas no passado caracterizam-se por serem robustas, com grande rigidez aos esforços horizontais. Esse fato, fez com que durante muitos anos, a verificação da estabilidade global fosse deixada de lado na maioria das construções.

Assim, o presente trabalho tem como objetivo estudar a estabilidade global nas estruturas de concreto armado em edifícios considerando os efeitos de segunda ordem nessas estruturas (efeitos não-lineares). Deu-se enfoque a edifícios com sistemas de contraventamento constituídos por associações de pórticos com paredes e/ou núcleos resistentes, sendo comparadas diferentes configurações estruturais possíveis para tais elementos de modo que atenda as prescrições estabelecidas pela norma NBR 6118 (ABNT, 2014).

\section{OBJETIVOS}

O presente trabalho buscou, para os principais sistemas de contraventamento utilizados em edifícios de concreto armado, variar os parâmetros de modelagens e critérios mais relevantes disponíveis no programa comercial
Altoqi Eberick V9 tais como: geometria dos pilares, consideração de coeficientes redutores de inércia para a verificação das não-linearidades físicas dos elementos estruturais e modificações na rigidez das ligações entre vigas e pilares. Tais variações foram realizadas, para a avaliação de suas influências nos deslocamentos laterais, parâmetro de instabilidade Gama z $\left(\gamma_{z}\right)$ esforços solicitantes nas fundações.

\section{FUNDAMENTOS TEÓRICOS}

A avaliação da estabilidade global de um elemento ou conjunto de elementos estruturais é um dos mais importantes fatores para a concepção estrutural, pois visa garantir a segurança da estrutura diante da perda de sua capacidade resistente, causada pelo aumento das deformações, em decorrência das ações horizontais e verticais. $\mathrm{Na}$ análise de estabilidade, os esforços calculados a partir da geometria inicial da estrutura, sem deformação, são chamados efeitos de primeira ordem. Aqueles advindos da deformação da estrutura são chamados de efeito de segunda ordem. A consideração dos efeitos de segunda ordem conduz à não-linearidade entre a ações e deformações; essa não-linearidade, devido sua origem, é chamada de não-linearidade geométrica. A fissuração e fluência do concreto levam também a uma não-linearidade (entre ações e deformações) chamada, neste caso, de não-linearidade física. (CHUST E MIRANDA,2013).

Quanto mais esbelta for à estrutura, maior será a necessidade da análise dos efeitos de segunda ordem, que podem ser determinados a partir de parâmetros de estabilidade práticos que auxiliam na decisão de considerar ou não os efeitos de 2 a ordem, sendo os previstos na norma brasileira o parâmetro $\alpha$ (alfa) e o coeficiente $\gamma_{z}$. A norma brasileira NBR 6118 (ABNT, 2014) dispensa o dimensionamento da estrutura considerando as solicitações de 2a ordem, desde que estas, sejam menores em intensidade que $10 \%$ das solicitações de 1a ordem. Ocorre que, para verificar esta condição, é necessária a realização de uma análise de 2 a ordem, independentemente de seus efeitos serem utilizados ou não para o dimensionamento da estrutura. 
O coeficiente de instabilidade $\gamma_{2}$ foi introduzido por Franco e Vasconcelos (1991), o qual mensura a sensibilidade da estrutura aos efeitos de 2a ordem, também podendo ser utilizado para majorar os efeitos de 1a ordem devido às cargas horizontais para obtenção de efeitos aproximados de $2^{\text {a }}$ ordem. $O$ coeficiente $\gamma_{z}$ é definido por meio da Equação 1:

$$
\gamma_{\mathrm{z}}=\frac{1}{1-\frac{\Delta \mathrm{M}_{\mathrm{d}}}{\mathrm{M}_{1 \mathrm{~d}}} * \frac{1}{1,1}}
$$

Sendo:

$\mathbf{M}_{1 \mathrm{~d}}$ = é o momento de tombamento, ou seja, a soma dos momentos de todas as forças horizontais da combinação considerada, com seus valores de cálculo, em relação à base da estrutura;

$\Delta \mathbf{M}_{\mathbf{d}}=$ é a soma dos produtos de todas as forças verticais atuantes na estrutura, na combinação considerada, com seus valores de cálculo, pelos deslocamentos horizontais de seus respectivos pontos de aplicação, obtidos da análise de $1^{\text {a }}$ ordem;.

Considera-se que a estrutura é de nós fixos se for obedecida a condição $\gamma_{2} \leq 1,1$, caso contrário a estrutura é classificada como de nós móveis chegando a instabilidade global para valores superiores a 1,3 .

Com a verticalização cada vez maior das edificações, torna-se cada vez mais importante o estudo do efeito da instabilidade global dos edifícios e os parâmetros que a influencia. Uma forma bastante efetiva para reduzir a instabilidade da edificação é a utilização de pilares-paredes no formato de " $U$ " ou " $L$ " convenientemente posicionados na planta da edificação, conferindo a esta a rigidez necessária em ambas às direções para estabilidade da mesma. Ocorre que lajes protendidas apresentam uma espessura mínima de dezesseis centímetros (Item 13.2.4.1 da NBR 6118 (ABNT, 2014), sendo comum o uso de pelo menos dezoito centímetros, o que garante o efeito de diafragma rígido e travamento dos pilares, assegurando que todos trabalhem juntos na estabilização da estrutura. No caso de lajes nervuradas, a elevada espessura da laje na região de ligação dos pilares com esta, torna este ponto da estrutura suficientemente rígido para estabilizar a edificação.

A NBR 6118 (ABNT, 2014) utiliza uma simplificação na consideração da não linearidade física. A rigidez dos elementos estruturais é alterada a partir de coeficientes de redução para cada tipo de elemento (vigas, pilares e lajes), de acordo com a influência que este elemento possui para a estabilidade global da estrutura. Esta rigidez reduzida pelo coeficiente é chamada de rigidez efetiva ou rigidez secante.

A norma supracitada torna obrigatória a consideração da não linearidade física e propõe os valores que devem ser adotados para redução da rigidez dos elementos estruturais, sendo estes:

$$
\begin{array}{ll}
\text { Lajes: }(E I)_{s e c}=0,3 E_{c i l c} & \text { Eq. [2] } \\
\text { Vigas: } & \\
\text { - }(E I)_{\text {sec }}=0,4 E_{c i l c} \text { para } A_{s}{ }^{\prime} \neq A_{s} & \text { Eq. [3] } \\
\text { - }(E I)_{\text {sec }}=0,5 E_{c i l c} \text { para } A_{s}{ }^{\prime}=A_{s} & \text { Eq. [4] }
\end{array}
$$

$$
\text { Pilares: }(\mathrm{EI})_{\mathrm{sec}}=0,8 \mathrm{E}_{\mathrm{cil}} \quad \text { Eq. [5] }
$$

Sendo:

$\mathbf{I}_{\mathbf{c}}:$ Momento de inércia da seção bruta de concreto; $\mathbf{E}_{\mathrm{ci}}$ : Módulo de deformação tangencial inicial do concreto;

As: Área da seção transversal da armadura longitudinal de tração;

As': Área da seção transversal da armadura longitudinal de compressão.

\section{MODELOS E RESULTADOS}

Para as análises em questão, foram considerados três tipologias de sistemas de contraventamento: pórticos, núcleos rígidos em formato " $U$ " e pilar-parede). Considerando para cada sistema dois diferentes tipos de ligações (rígidas e semi-rígidas), totalizando desta forma 6 (seis) modelos em estudo para um edifício fictício com ordem de esbeltez de um para quatro, ou seja, considerando uma largura de aproximadamente $13 \mathrm{~m}$ entre os pilares de extremidade, adotou-se uma altura com cerca de $52 \mathrm{~m}$. 
Para os modelos analisados, algumas variáveis foram pré-definidas tais como:

- Os painéis de lajes nervuradas do tipo (Cubetas) B40/80/80 (cm), são montados e calculados de forma independente do pórtico. As reações das lajes são transmitidas às vigas em que se apoiam. Assim, é feito o processamento e montagem do pórtico espacial da estrutura, recebendo o carregamento calculado pelas lajes. Estudos recentes feitos por Feitosa e Alves (2015) e Passos et al (2015), mostram a influência na consideração da rigidez da laje no cálculo do parâmetro $\gamma_{z}$ para edificações com ordem de esbeltez de um para quatro e um para seis, considerando sistemas estruturais em lajes maciças e lajes nervuradas.

- Efeito de segunda ordem gerados pela não-linearidade física considerados de forma simplificada, através de redutores da inércia dos elementos de concreto previsto na norma brasileira NBR 6118 (ABNT, 2014), para todos os modelos estudados.

- Análise de um número limitado de configurações estruturais, porém considerados suficiente para a satisfação do objetivo proposto.

Nos modelos estudados, utilizou-se para a resistência característica do concreto o valor de $\mathrm{f}_{\mathrm{ck}}=$ $30 \mathrm{MPa}$, agressividade ambiental II, diâmetro de agregado igual a $19 \mathrm{~mm}$ e os cobrimentos nominais para os elementos estruturais conforme indicados na NBR 6118 (ABNT, 2014).

O software calcula de forma automática os pesos próprios dos elementos estruturais, de acordo com as dimensões definidas no modelador estrutural para pilares, lajes e vigas. Para as cargas permanentes foi atribuído o valor de $1,5 \mathrm{kN} / \mathrm{m}^{2} \mathrm{e}$ $2,0 \mathrm{kN} / \mathrm{m}^{2}$ para cargas acidentais previstos na norma brasileira NBR 6120 (ABNT, 1980). Foram escolhidos, para todos os exemplos, blocos cerâmicos de vedação com $15 \mathrm{~cm}$ de largura e peso específico de $13 \mathrm{kN} / \mathrm{m}^{3}$ sobre vigas e lajes conforme o projeto arquitetônico. As fundações foram consideradas engastadas em suas bases. A Figura 1 apresenta uma vista do edifício fictício em estudo.

A ação horizontal considerada foi a do vento conforme a NBR 6123 (ABNT, 1988). A velocidade básica é de $32 \mathrm{~m} / \mathrm{s}$, o fator do
Topográfico (S1) igual a 1,0, considerando terreno plano ou fracamente acidentado, Categoria de rugosidade IV (S2), Classe da edificação B (S2) e Fator estatístico (S3) igual a 1,0 (edificações para hotéis e residências) e os respectivos coeficientes de arrasto para cada direção. Os sentidos da aplicação do vento que foram utilizados são a $0^{\circ}(\mathrm{V} 1)$, $180^{\circ}(\mathrm{V} 2), 90^{\circ}$ (V3) e $270^{\circ}(\mathrm{V} 4)$, conforme a Figura 2.

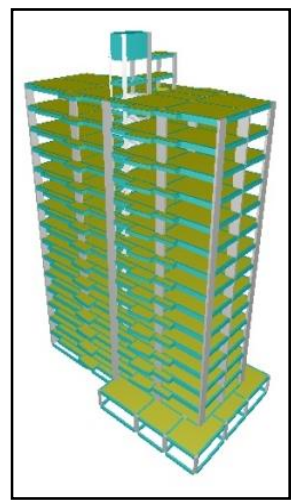

FIGURA 1: Perspectiva em 3D FONTE: Autor (2016).

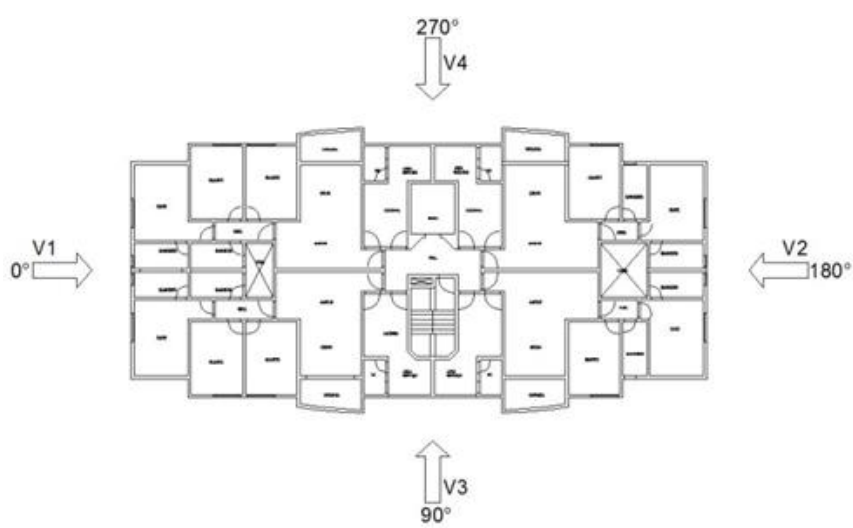

FIGURA 2: Sentido de aplicação do vento na estrutura FONTE: Autor (2016).

\subsection{MODELOS DE APLICAÇÃO}

\subsubsection{Modelo 1}

Parte-se de um modelo nomeado 1, constituído unicamente por pórticos com todas as ligações rígidas, representado na Figura 3, onde variou-se a seção transversal dos pilares até que fosse atingido um valor próximo do limite do coeficiente $\gamma_{2}(1,3)$ preconizado pela NBR 6118 (ABNT, 2014) podendo desta forma, considerar os esforços globais de $2^{a}$ a ordem para em seguida serem incorporados núcleos resistentes em formato "U" e pilares-parede, obtendo-se assim resultados e percentuais diferentes para cada caso. 


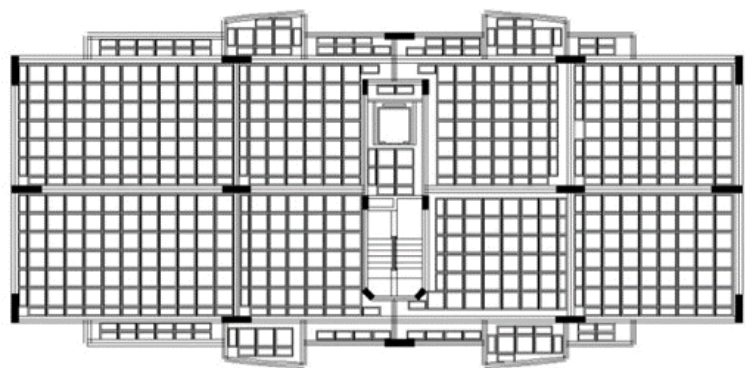

FIGURA 3: Planta baixa modelo em pórtico FONTE: Autor (2016).

O deslocamento limite no topo da edificação deve ser calculado como sendo $H / 1700$ de acordo com a tabela 13.3 da NBR 6118 (ABNT, 2014), onde $H$ é a altura da edificação. Como $\mathrm{H}=5.145,00 \mathrm{~cm}$ tem-se 5145/1700 $=3,03 \mathrm{~cm}$, apresentado na Tabela 1 na linha Deslocamento limite. 0 deslocamento horizontal Médio 1a ordem obtido no topo da estrutura é calculado pelo programa através do método dos deslocamentos, considerando apenas o carregamento horizontal do vento nas direções $x$ e $y$. O Deslocamento combinações frequente é causado pela ação do vento para combinação frequente $\left(\gamma_{\mathrm{f} 2}=0,30\right)$ conforme também definido na tabela 13.3 da NBR 6118 (ABNT, 2014), portanto deve-se multiplicar o deslocamento horizontal Médio 1 a ordem pelo fator $\gamma_{\mathrm{f} 2}$ para obter o deslocamento combinações frequentes e em seguida pode-se compará-lo ao deslocamento limite.

Através da planta de carga gerada pelo Software EBERICK representada pela Tabela 2, pode-se avaliar os esforços solicitantes gerados na fundação para o sistema de contraventamento em pórtico com ligações rígidas.

Devido à configuração da estrutura, como os resultados dos deslocamentos horizontais ao longo da edificação obtidos pelo software computacional EBERICK e apresentados no gráfico da figura 4 para o vento a $0^{\circ}$ (V1) e a $180^{\circ}$ (V2) apresentam praticamente os mesmos resultados, assim como os resultados obtidos para o vento a $90^{\circ}$ (V3) e a $270^{\circ}$ (V4), somente serão apresentados os valores obtidos com o vento atuando nas direções a $0^{\circ}$ (direção $\mathrm{X}$ ) ou $90^{\circ}$ (direção $\mathrm{Y}$ ) considerando para todos os modelos apresentados, os efeitos de segunda ordem.

Os resultados da análise de estabilidade global da estrutura para o parâmetro $\gamma_{2}$ encontrados pelo software computacional EBERICK, também pode ser observado pela figura 4. Para todos os modelos estudados, foi considerada a combinação para ELU conforme indicado na Equação 6.

$$
\begin{array}{r}
1.3 \mathrm{G} 1+1.4 \mathrm{G} 2+1.4 \mathrm{~S}+1.4 \mathrm{Q}+1.2 \mathrm{~A} \\
+0.84 \mathrm{~V} 1+0.35 \mathrm{D} 1
\end{array}
$$

Onde:

G1= peso próprio

G2= adicional

$\mathrm{S}=$ solo

$\mathbf{Q}=$ acidental

$A=$ água

V1= vento 0 은

D1= desaprumo 0응

\begin{tabular}{|c|c|c|c|c|}
\hline Verificações & $0^{\circ}$ & $180^{\circ}$ & $90^{\circ}$ & $270^{\circ}$ \\
\hline Altura total da edificação $(\mathrm{cm})$ & \multicolumn{4}{|c|}{$5.145,00$} \\
\hline Deslocamento limite $(\mathrm{cm})$ & \multicolumn{4}{|c|}{3,03} \\
\hline Deslocamento horizontal Médios 1a ordem $(\mathrm{cm})$ & 2,12 & $-2,12$ & 4,78 & $-4,78$ \\
\hline$\gamma_{\mathrm{f} 2}$ & 0,3 & 0,3 & 0,3 & 0,3 \\
\hline Deslocamento combinações frequentes $(\mathrm{cm})$ & 0,64 & $-0,64$ & 1,43 & $-1,43$ \\
\hline Deslocamento horizontal Médios 1a ordem $+2^{\mathrm{a}}$ ordem $(\mathrm{cm})$ & 2,35 & $-2,35$ & 5,45 & $-5,45$ \\
\hline Variação do Deslocamento no topo da edificação (\%) & 10,78 & 10,78 & 13,99 & 13,99 \\
\hline
\end{tabular}

TABELA 1: Deslocamentos horizontais devido a ação do vento no topo do edifício - Pórtico ligações rígidas. 
TABELA 2: Sistema em pórticos - Esforços solicitantes de cálculo em pilares com ligações rígidas.

\begin{tabular}{|c|c|c|c|c|c|c|c|}
\hline Nome & Seção $(\mathrm{cm})$ & Carga Máx. (kN) & $M x(k N . m)$ & My (kN.m) & Fx (kN) & Fy $(k N)$ & oméd $\left(\mathrm{kN} / \mathrm{cm}^{2}\right)$ \\
\hline P1 & $30 \times 125$ & 4551,00 & 902 & 31 & 9 & 165 & 1,21 \\
\hline $\mathbf{P 2}$ & $30 \times 125$ & 7410,00 & 67 & 280 & 49 & 17 & 1,98 \\
\hline P3 & $30 \times 125$ & 5457,00 & 82 & 286 & 53 & 36 & 1,46 \\
\hline P4 & $30 \times 130$ & 5466,00 & 76 & 349 & 61 & 22 & 1,40 \\
\hline P5 & $30 \times 125$ & 7855,00 & 67 & 306 & 80 & 15 & 2,09 \\
\hline P6 & $30 \times 120$ & 5958,00 & 72 & 240 & 47 & 27 & 1,66 \\
\hline P7 & $30 \times 125$ & 4506,00 & 896 & 29 & 8 & 150 & 1,20 \\
\hline P8 & $30 \times 125$ & 7308,00 & 67 & 253 & 49 & 17 & 1,95 \\
\hline P9 & $30 \times 125$ & 6076,00 & 73 & 277 & 77 & 27 & 1,62 \\
\hline P10 & $25 \times 65$ & 3107,00 & 141 & 7 & 3 & 58 & 1,91 \\
\hline P11 & $25 \times 65$ & 2833,00 & 142 & 7 & 3 & 38 & 1,74 \\
\hline P12 & $25 \times 70$ & 2451,00 & 141 & 9 & 4 & 38 & 1,40 \\
\hline P13 & $25 \times 65$ & 2912,00 & 144 & 8 & 4 & 60 & 1,79 \\
\hline P14 & $25 \times 55$ & 2605,00 & 58 & 43 & 22 & 25 & 1,89 \\
\hline P15 & $25 \times 50$ & 2540,00 & 42 & 24 & 10 & 16 & 2,03 \\
\hline P16 & $30 \times 125$ & 4613,00 & 103 & 264 & 45 & 53 & 1,23 \\
\hline P17 & $30 \times 125$ & 5224,00 & 93 & 232 & 47 & 45 & 1,39 \\
\hline P18 & $30 \times 120$ & 3375,00 & 617 & 21 & 7 & 114 & 0,94 \\
\hline P19 & $30 \times 130$ & 4299,00 & 58 & 295 & 60 & 17 & 1,10 \\
\hline P20 & $30 \times 120$ & 3155,00 & 614 & 28 & 11 & 121 & 0,88 \\
\hline
\end{tabular}

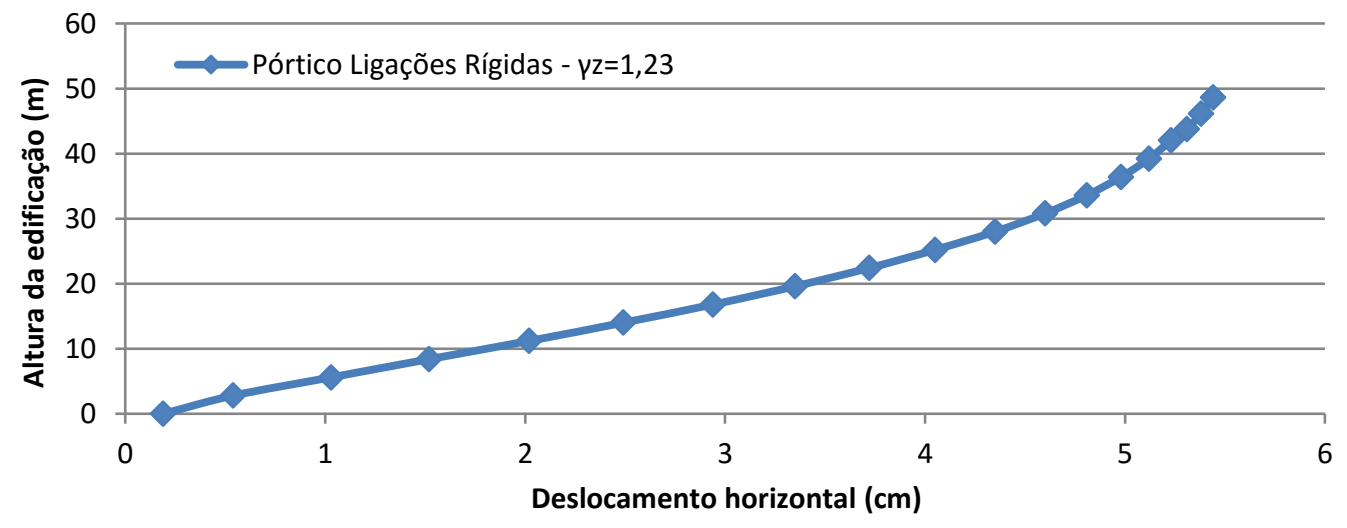

FIGURA 4: Deslocamento Horizontal - Modelo 1. FONTE: Autor (2016).

\subsubsection{Modelo 2}

Para o segundo modelo foram consideradas ligações semi-rígidas entre pilares e vigas com $15 \%$ de redução na rigidez mantendo o que fica estabelecido no item 14.6.4.3 da NBR 6118 (ABNT, 2014), onde os valores de redistribuição ficam limitados a $10 \%$ para estruturas de nós fixos e $25 \%$ para estruturas de nós móveis. As dimensões dos elementos foram mantidas iguais ao do Modelo 1, avaliando-se então a influência da rigidez da ligação.

Os valores dos deslocamentos da análise de primeira e segunda ordem no topo do edifício, bem como a variação do deslocamento no topo da edificação devido as ações característica nas duas direções para o sistema em pórticos com ligações semi-rígidas estão apresentados na Tabela 3. 
TABELA 3: Deslocamentos horizontais devido a ação do vento no topo do edifício - pórtico ligações semi-rígidas.

\begin{tabular}{|c|c|c|c|c|}
\hline Verificações & $0^{\circ}$ & $180^{\circ}$ & $90^{\circ}$ & $270^{\circ}$ \\
\hline Altura total da edificação $(\mathrm{cm})$ & \multicolumn{4}{|c|}{$5.145,00$} \\
\hline Deslocamento limite (cm) & \multicolumn{4}{|c|}{3,03} \\
\hline Deslocamento horizontal Médios 1a ordem (cm) & 2,56 & $-2,56$ & 6,23 & $-6,23$ \\
\hline$\gamma_{\mathrm{f} 2}$ & 0,3 & 0,3 & 0,3 & 0,3 \\
\hline Deslocamento combinações frequentes $(\mathrm{cm})$ & 0,77 & $-0,77$ & 1,87 & $-1,87$ \\
\hline Deslocamento horizontal Médios 1a ordem $+2^{\mathrm{a}}$ ordem $(\mathrm{cm})$ & 2,92 & $-2,92$ & 7,46 & $-7,46$ \\
\hline Variação do Deslocamento no topo da edificação (\%) & 14,05 & 14,05 & 19,8 & 19,8 \\
\hline
\end{tabular}

Por meio da planta de carga gerada pelo Software EBERICK representada pela Tabela 4, pode-se avaliar os esforços solicitantes gerados na fundação para o sistema de contraventamento em pórtico com ligações semi-rígidas.

Fazendo uma comparação com os dois modelos até então apresentados percebe-se que, ao flexibilizar as ligações por meio de ligações semi-rígidas, há uma perda da rigidez do sistema, evidenciado pelo aumento no valor do $\gamma_{z}$ passando para 1,26, bem como os deslocamentos horizontais no topo da edificação representado pela Figura 5. Resultando então, em um acréscimo no custo para fundação devido ao aumento dos esforços solicitantes, que pode ser observado comparando as Tabelas 2 e 4.

TABELA 4: Sistema em pórticos - Esforços solicitantes de cálculo em pilares com ligações semi-rígidas.

\begin{tabular}{|c|c|c|c|c|c|c|c|}
\hline Nome & Seção $(\mathrm{cm})$ & Carga Máx. (kN) & Mx (kN.m) & My (kN.m) & Fx (kN) & Fy (kN) & oméd $\left(\mathrm{kN} / \mathrm{cm}^{2}\right)$ \\
\hline P1 & $30 \times 125$ & 4546,00 & 1001 & 32 & 8 & 172 & 1,21 \\
\hline P2 & $30 \times 125$ & 7427,00 & 74 & 302 & 47 & 18 & 1,98 \\
\hline P3 & $30 \times 125$ & 5439,00 & 90 & 316 & 50 & 39 & 1,45 \\
\hline P4 & $30 \times 130$ & 5472,00 & 85 & 369 & 57 & 24 & 1,40 \\
\hline P5 & $30 \times 125$ & 7872,00 & 76 & 330 & 79 & 17 & 2,10 \\
\hline P6 & $30 \times 120$ & 5946,00 & 78 & 254 & 49 & 28 & 1,65 \\
\hline P7 & $30 \times 125$ & 4461,00 & 1001 & 30 & 8 & 159 & 1,19 \\
\hline P8 & $30 \times 125$ & 7312,00 & 75 & 286 & 43 & 17 & 1,95 \\
\hline P9 & $30 \times 125$ & 6085,00 & 80 & 295 & 73 & 28 & 1,62 \\
\hline P10 & $25 \times 65$ & 3252,00 & 143 & 21 & 17 & 52 & 2,00 \\
\hline P11 & $25 \times 65$ & 2890,00 & 147 & 11 & 6 & 55 & 1,78 \\
\hline P12 & $25 \times 70$ & 2638,00 & 162 & 10 & 3 & 42 & 1,51 \\
\hline P13 & $25 \times 65$ & 3006,00 & 150 & 10 & 4 & 60 & 1,85 \\
\hline P14 & $25 \times 55$ & 2855,00 & 72 & 56 & 19 & 21 & 2,08 \\
\hline P15 & $25 \times 50$ & 2901,00 & 65 & 42 & 20 & 26 & 2,32 \\
\hline P16 & $30 \times 125$ & 4271,00 & 103 & 285 & 46 & 51 & 1,14 \\
\hline P17 & $30 \times 125$ & 4802,00 & 94 & 254 & 46 & 44 & 1,28 \\
\hline P18 & $30 \times 120$ & 3403,00 & 659 & 23 & 7 & 102 & 0,95 \\
\hline P19 & $30 \times 130$ & 4292,00 & 62 & 319 & 59 & 18 & 1,10 \\
\hline P20 & $30 \times 120$ & 3159,00 & 653 & 29 & 12 & 108 & 0,88 \\
\hline
\end{tabular}




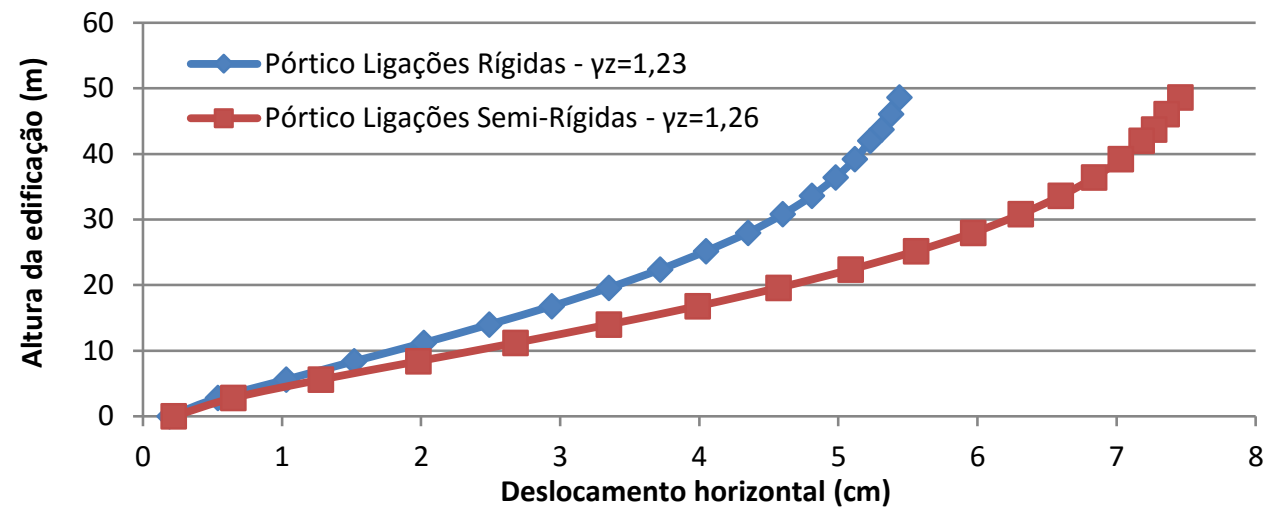

FIGURA 5: Deslocamento Horizontal - Modelos 1,2. FONTE: Autor (2016).

\subsubsection{Modelo 3}

Para avaliar a influência do núcleo rígido na rigidez da estrutura, o Modelo 3 consiste na introdução de um núcleo resistente à estrutura do Modelo 1, mantendo-se as ligações rígidas entre vigas e pilares, carregamento de vento e as cargas recebidas pelas vigas. Esse núcleo corresponde a um grande pilar em formato de " $\mathrm{U}$ ", com dimensões externas de 2,70 $\mathrm{m} \times 2,10 \mathrm{~m}$, e espessura de $20 \mathrm{~cm}$, representado na Figura 6 . Foram removidos os pilares 12 e 13, pois os mesmos se encontravam na mesma área onde foi inserido o núcleo rígido.

Os resultados referentes aos deslocamentos da análise de primeira e segunda ordem no topo do edifício, bem como a variação do deslocamento no topo da edificação devido as ações característica nas duas direções para o sistema em núcleo rígido "U" com ligações rígidas estão apresentados na Tabela 5.

Por meio da planta de carga gerada pelo Software EBERICK representada pela Tabela 6 , pode-se avaliar os esforços solicitantes gerados na fundação para o sistema de contraventamento em Núcleo Rígido "U” com ligações rígidas.

Verifica-se que os deslocamentos horizontais e o parâmetro de instabilidade $\gamma_{2}$ diminuíram consideravelmente quando comparado com o sistema em pórtico demonstrados no gráfico da Figura 7, isso porque a rigidez do edifício como um todo aumentou devido ao acréscimo do núcleo. A metodologia de lançamento do núcleo rígido, adotada pelo software EBERICK, consta em utilizar barras rígidas para a transferência dos esforços, o que confere uma maior rigidez as estruturas.

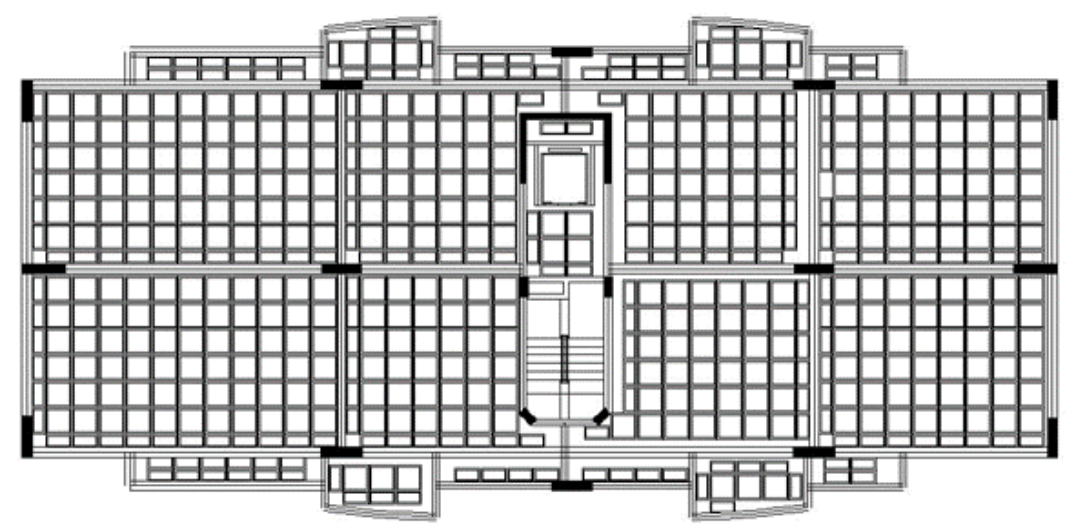

FIGURA 6: Planta baixa modelo núcleo rígido em formato "U" FONTE: Autor (2016). 
TABELA 5: Deslocamentos horizontais devido a ação do vento no topo do edifício núcleo rígido "U" - ligações rígidas.

\begin{tabular}{|c|c|c|c|c|}
\hline Verificações & $0^{\circ}$ & $180^{\circ}$ & $90^{\circ}$ & $270^{\circ}$ \\
\hline Altura total da edificação $(\mathrm{cm})$ & \multicolumn{4}{|c|}{5145,00} \\
\hline Deslocamento limite (cm) & \multicolumn{4}{|c|}{3,03} \\
\hline Deslocamento horizontal Médios 1a ordem $(\mathrm{cm})$ & 2 & 2 & 4,14 & $-4,14$ \\
\hline$\gamma_{\mathrm{f} 2}$ & 0,3 & 0,3 & 0,3 & 0,3 \\
\hline Deslocamento combinações frequentes $(\mathrm{cm})$ & 0,6 & $-0,6$ & 1,24 & $-1,24$ \\
\hline Deslocamento horizontal Médios 1a ordem $+2 \underline{a}$ ordem $(\mathrm{cm})$ & 2,16 & $-2,16$ & 4,55 & $-4,55$ \\
\hline Variação do Deslocamento no topo da edificação (\%) & 7,9 & 7,9 & 9,78 & 9,78 \\
\hline
\end{tabular}

TABELA 6: Sistema em núcleo rígido "U" - Esforços solicitantes de cálculo em pilares com ligações rígidas.

\begin{tabular}{|c|c|c|c|c|c|c|c|}
\hline Nome & Seção $(\mathrm{cm})$ & $\begin{array}{c}\text { Carga Máx. } \\
(\mathbf{k N})\end{array}$ & Mx (kN.m) & My (kN.m) & Fx (kN) & Fy (kN) & $\begin{array}{c}\text { oméd } \\
\left(\mathrm{kN} / \mathrm{cm}^{2}\right)\end{array}$ \\
\hline P1 & $30 \times 125$ & 4441,00 & 521 & 20 & 7 & 85 & 1,18 \\
\hline P2 & $30 \times 125$ & 7296,00 & 40 & 115 & 19 & 12 & 1,95 \\
\hline P3 & $30 \times 125$ & 6003,00 & 49 & 113 & 20 & 20 & 1,60 \\
\hline P4 & $30 \times 130$ & 5417,00 & 45 & 190 & 37 & 13 & 1,39 \\
\hline P5 & $30 \times 125$ & 7784,00 & 41 & 162 & 56 & 10 & 2,08 \\
\hline P6 & $30 \times 120$ & 6657,00 & 41 & 118 & 23 & 13 & 1,85 \\
\hline P7 & $30 \times 125$ & 4412,00 & 522 & 21 & 7 & 86 & 1,18 \\
\hline P8 & $30 \times 125$ & 7247,00 & 42 & 159 & 29 & 11 & 1,93 \\
\hline P9 & $30 \times 125$ & 6095,00 & 49 & 193 & 54 & 19 & 1,63 \\
\hline P10 & $25 \times 65$ & 2384,00 & 79 & 4 & 2 & 34 & 1,47 \\
\hline P11 & $25 \times 65$ & 2346,00 & 68 & 4 & 2 & 25 & 1,44 \\
\hline P14 & $25 \times 55$ & 2373,00 & 35 & 27 & 15 & 17 & 1,73 \\
\hline P15 & $25 \times 50$ & 2322,00 & 23 & 12 & 5 & 8 & 1,86 \\
\hline P16 & $30 \times 125$ & 4462,00 & 45 & 111 & 19 & 21 & 1,19 \\
\hline P17 & $30 \times 125$ & 5107,00 & 61 & 161 & 30 & 31 & 1,36 \\
\hline P18 & $30 \times 120$ & 3411,00 & 347 & 13 & 5 & 51 & 0,95 \\
\hline P19 & $30 \times 130$ & 4452,00 & 33 & 157 & 32 & 9 & 1,14 \\
\hline P20 & $30 \times 120$ & 3243,00 & 356 & 17 & 7 & 59 & 0,90 \\
\hline P21 & U $210 \times 270 \times 20 \times 20$ & 10692,00 & 5108 & 3746 & 318 & 755 & 0,82 \\
\hline
\end{tabular}




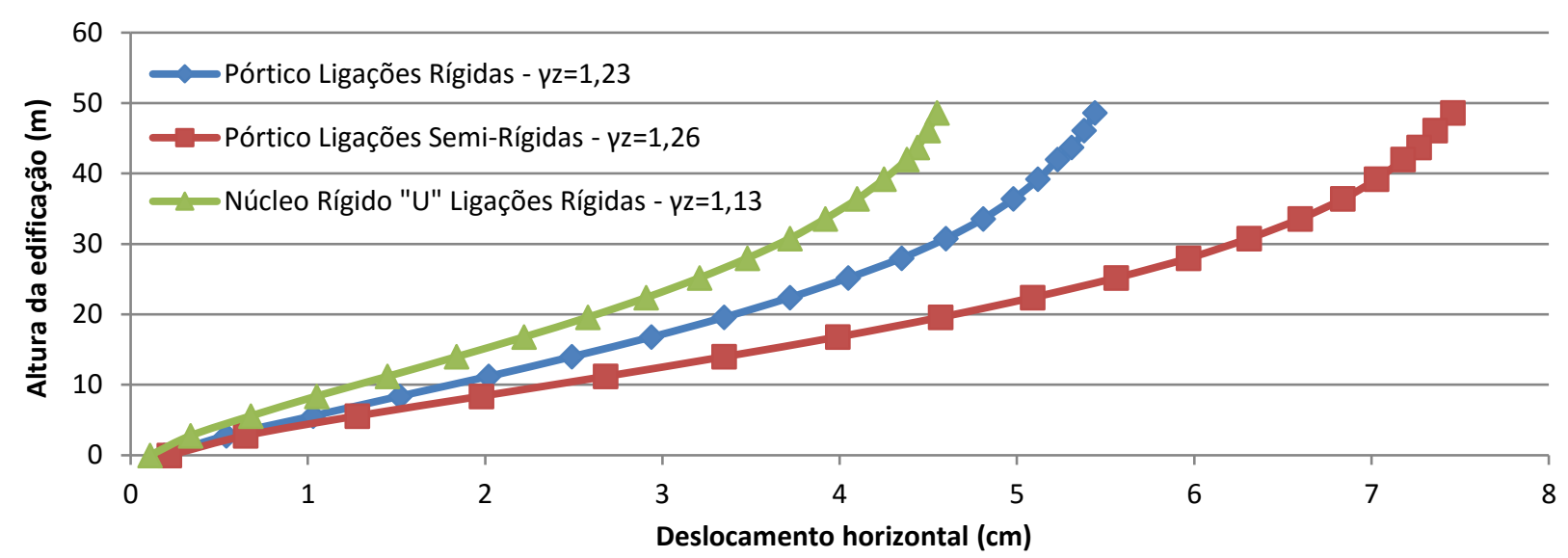

FIGURA 7: Deslocamento Horizontal - Modelos 1,2,3. FONTE: Autor (2016).

Entretanto, em uma estrutura com cerca de 20 pavimentos é esperado que os esforços nas fundações sejam elevados. Todavia, nesse projeto chama a atenção que o núcleo rígido em formato de "U" esta com carga vertical da ordem de $10.000 \mathrm{kN}$ e momentos de até $5.108,00 \mathrm{kN}$.m. Além disso, apresentou forças horizontais elevadas, atingindo até $755 \mathrm{kN}$ representados na Tabela 6 .

\subsubsection{Modelo 4}

Nesse modelo foi estudada uma situação oposta à do projeto anterior. Assim, partindo do projeto com núcleo rígido em formato " $\mathrm{U}$ " com ligações rígidas, procurou-se flexibilizar a estrutura através da inclusão de nós semi-rígidos com $15 \%$ de redução na rigidez em todas as extremidades de vigas, mesmo nas vigas que apoiam em pilares, mantendo todas as dimensões das peças e configurações, afim de avaliar a influência dos pórticos rígidos no desempenho global da estrutura.

Os valores referentes aos deslocamentos da análise de primeira e segunda ordem no topo do edifício, bem como a variação do deslocamento no topo da edificação devido as ações característica nas duas direções para o sistema em núcleo rígido " $U$ " com ligações semi-rígidas estão apresentados na Tabela 7.

Através da planta de carga gerada pelo Software EBERICK representada pela tabela 8, podese avaliar os esforços solicitantes gerados na fundação para o sistema de contraventamento com núcleo rígido "U" - ligações semi-rígidas.

Percebe-se pelo gráfico da figura 8 que ao considerar as ligações semi-rígidas, a estrutura teve sensível redução na rigidez, com um aumento de cerca de $31 \%$ nos deslocamentos de 2 a ordem. Visto que o equilíbrio da estrutura passa a contar com uma menor contribuição pelo sistema em pórticos. Analogamente ao Modelo 2, os aumentos anteriormente citados ocasionará em um acréscimo no custo para fundação devido ao aumento dos esforços solicitantes, que também pode ser observado comparando as Tabelas 6 e 8 .

\begin{tabular}{|c|c|c|c|c|}
\hline Verificações & $0^{\circ}$ & $180^{\circ}$ & $90^{\circ}$ & $270^{\circ}$ \\
\hline Altura total da edificação (cm) & \multicolumn{4}{|c|}{$5.145,00$} \\
\hline Deslocamento limite $(\mathrm{cm})$ & \multicolumn{4}{|c|}{3,03} \\
\hline Deslocamento horizontal Médios 1a ordem $(\mathrm{cm})$ & 2,4 & $-2,4$ & 5,27 & $-5,27$ \\
\hline$\gamma_{\mathrm{f} 2}$ & 0,3 & 0,3 & 0,3 & 0,3 \\
\hline Deslocamento combinações frequentes $(\mathrm{cm})$ & 0,72 & $-0,72$ & 1,58 & $-1,58$ \\
\hline Deslocamento horizontal Médios 1a ordem +2 a ordem $(\mathrm{cm})$ & 2,64 & $-2,64$ & 5,94 & $-5,94$ \\
\hline Variação do Deslocamento no topo da edificação (\%) & 10,15 & 10,15 & 12,87 & 12,87 \\
\hline
\end{tabular}


TABELA 8: Sistema em núcleo rígido "U" - Esforços solicitantes de cálculo em pilares com ligações semi-rígidas

\begin{tabular}{|c|c|c|c|c|c|c|c|}
\hline Nome & Seção $(\mathrm{cm})$ & Carga Máx. (kN) & $M x(k N . m)$ & $\begin{array}{c}\text { My } \\
\text { (kN.m) }\end{array}$ & Fx (kN) & Fy $(k N)$ & $\begin{array}{c}\text { oméd } \\
\left(\mathrm{kN} / \mathrm{cm}^{2}\right)\end{array}$ \\
\hline P1 & $30 \times 125$ & 4419,00 & 625 & 24 & 1 & 3 & 1,18 \\
\hline $\mathbf{P 2}$ & $30 \times 125$ & 7367,00 & 51 & 132 & 22 & 12 & 1,96 \\
\hline P3 & $30 \times 125$ & 6178,00 & 56 & 124 & 20 & 20 & 1,65 \\
\hline P4 & $30 \times 130$ & 5432,00 & 54 & 228 & 1 & 5 & 1,39 \\
\hline P5 & $30 \times 125$ & 7823,00 & 49 & 175 & 50 & 8 & 2,09 \\
\hline P6 & $30 \times 120$ & 6633,00 & 49 & 131 & 18 & 14 & 1,84 \\
\hline P7 & $30 \times 125$ & 4344,00 & 658 & 24 & 7 & 85 & 1,16 \\
\hline P8 & $30 \times 125$ & 7248,00 & 51 & 198 & 35 & 12 & 1,93 \\
\hline P9 & $30 \times 125$ & 6140,00 & 55 & 234 & 61 & 18 & 1,64 \\
\hline P10 & $25 \times 65$ & 2473,00 & 92 & 4 & 2 & 34 & 1,52 \\
\hline P11 & $25 \times 65$ & 2491,00 & 80 & 4 & 1 & 23 & 1,53 \\
\hline P14 & $25 \times 55$ & 2569,00 & 42 & 33 & 17 & 18 & 1,87 \\
\hline P15 & $25 \times 50$ & 2529,00 & 26 & 14 & 5 & 7 & 2,02 \\
\hline P16 & $30 \times 125$ & 4544,00 & 48 & 120 & 18 & 17 & 1,21 \\
\hline P17 & $30 \times 125$ & 4761,00 & 64 & 198 & 34 & 28 & 1,27 \\
\hline P18 & $30 \times 120$ & 3396,00 & 373 & 14 & 7 & 26 & 0,94 \\
\hline P19 & $30 \times 130$ & 4411,00 & 40 & 189 & 50 & 3 & 1,13 \\
\hline P20 & $30 \times 120$ & 3218,00 & 428 & 21 & 15 & 2 & 0,89 \\
\hline P21 & U $210 \times 270 \times 20 \times 20$ & 11015,00 & 6596 & 4279 & 382 & 937 & 0,85 \\
\hline
\end{tabular}

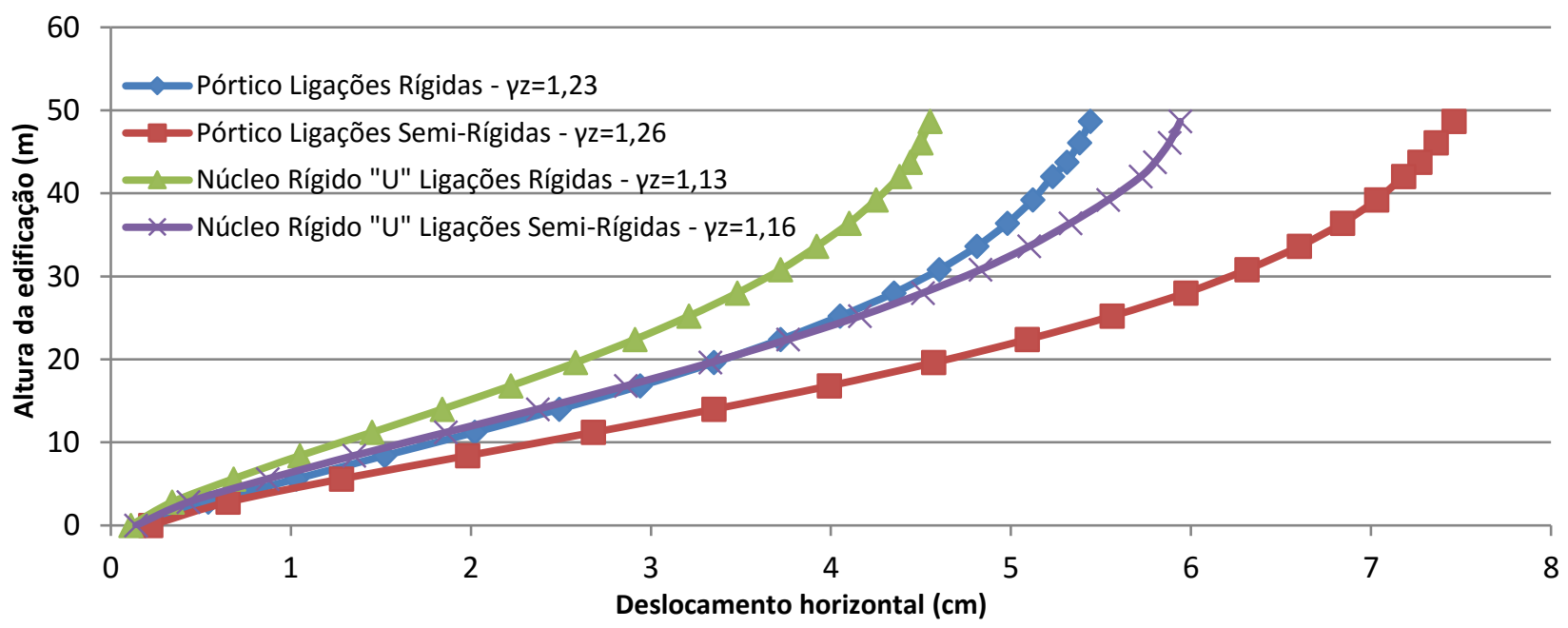

FIGURA 8: Deslocamento Horizontal - Modelos 1,2,3,4.

FONTE: Autor (2016).

Embora haja um significativo aumento nos deslocamentos e nos esforços das fundações, a eficiência do Núcleo Rígido formados por ligações semi-rígidas continuam sendo suficientes para manter a estabilidade da edificação, pois o valor do parâmetro de instabilidade $v_{z}$ encontrado igual a $(1,16)$ está dentro dos limites aceitáveis pela norma
NBR 6118 (ABNT, 2014) - (1,30), sendo a estrutura considerada estável.

\subsubsection{Modelo 5}

Apesar de serem sistemas muito eficientes para contraventamento da estrutura, a adoção de núcleos rígidos em formato "U" geram complicações 
para a execução das fundações, que passam a ter esforços muito grandes e, consequentemente, de difícil solução.

Neste modelo propõe substituir o núcleo rígido em formato " $U$ " por dois pilares-paredes retangular com seção de 20 x 190 cm, representado na Figura 9, mantendo as ligações rígidas e ajustando as vigas desse pavimento para manter a geometria do pavimento, a fim de avaliar os novos resultados dos parâmetros de instabilidade e os esforços na fundação.

Os valores referentes aos deslocamentos horizontais na análise de primeira e segunda ordem no topo do edifício, bem como a variação do deslocamento no topo da edificação devido as ações característica nas duas direções para o sistema em pilar parede - ligações rígidas estão apresentados na Tabela 9.

Através da planta de carga gerada pelo Software EBERICK representada pela Tabela 10, pode-se avaliar os esforços solicitantes gerados na fundação para o sistema de contraventamento com pilar parede - ligações rígidas.

A redução expressiva na dimensão do núcleo rígido implicou em uma expressiva redução nos esforços solicitantes da fundação que é notado ao comparar as Tabelas 6 e 10. Em contrapartida, houve um acréscimo de $26 \%$ nos deslocamentos devidos aos efeitos de 2a a ordem, que estão apresentados no gráfico da Figura 10. Esses valores, apesar de maiores, podem ser perfeitamente aceitos, pois ainda há uma grande reserva de capacidade resistente aos efeitos horizontais da estrutura, verificamos tal afirmação ao analisarmos os deslocamentos horizontais para combinação frequente $(1,51 \mathrm{~cm})$ que está abaixo do limite normativo $(3,03 \mathrm{~cm})$, demostrados na Tabela 9, Assim como o valor do parâmetro de instabilidade 国 ${ }_{\mathrm{z}}$ encontrado igual a $(1,20)$ também representado pela Figura 10.

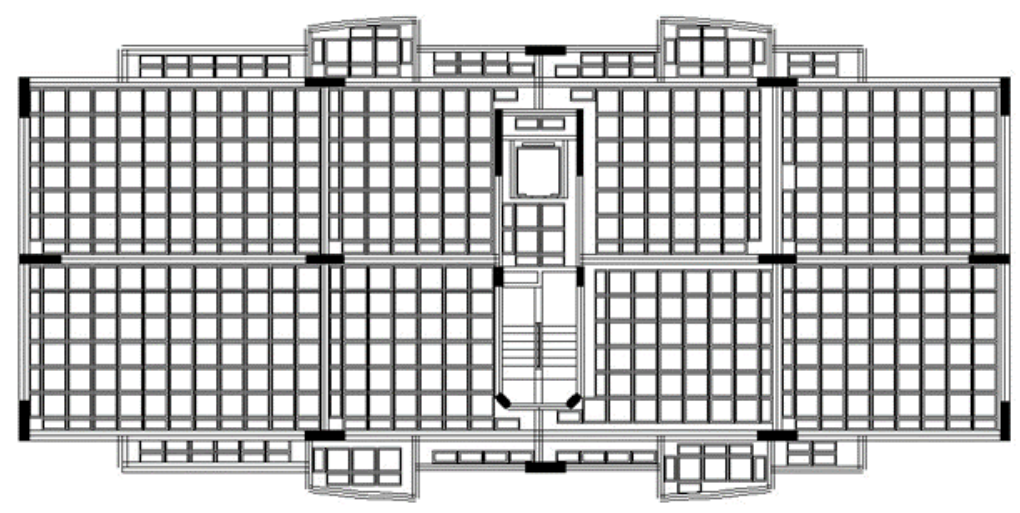

FIGURA 9: Planta baixa modelo pilar parede.

FONTE: Autor (2016).

Tabela 9: Deslocamentos horizontais devido a ação do vento no topo do edifício - pilar parede - ligações rígidas.

\begin{tabular}{|c|c|c|c|c|}
\hline Verificações & $0^{\circ}$ & $180^{\circ}$ & $90^{\circ}$ & $270^{\circ}$ \\
\hline Altura total da edificação $(\mathrm{cm})$ & \multicolumn{4}{|c|}{$5.145,00$} \\
\hline Deslocamento limite (cm) & \multicolumn{4}{|c|}{3,03} \\
\hline Deslocamento horizontal Médios 1a ordem $(\mathrm{cm})$ & 2,24 & $-2,24$ & 5,03 & $-5,03$ \\
\hline$\gamma_{\mathrm{f} 2}$ & 0,3 & 0,3 & 0,3 & 0,3 \\
\hline Deslocamento combinações frequentes $(\mathrm{cm})$ & 0,67 & $-0,67$ & 1,51 & $-1,51$ \\
\hline Deslocamento horizontal Médios 1a ordem +2 a ordem $(\mathrm{cm})$ & 2,49 & $-2,49$ & 5,75 & $-5,75$ \\
\hline Variação do Deslocamento no topo da edificação (\%) & 11,16 & 11,16 & 14,39 & 14,39 \\
\hline
\end{tabular}




\section{TABELA 10: Sistema em pilar parede - Esforços solicitantes de cálculo em pilares com ligações rígidas.}

\begin{tabular}{|c|c|c|c|c|c|c|c|}
\hline Nome & Seção $(\mathrm{cm})$ & Carga Máx. (kN) & $\mathrm{Mx}$ (kN.m) & My (kN.m) & Fx (kN) & Fy (kN) & oméd $\left(\mathrm{kN} / \mathrm{cm}^{2}\right)$ \\
\hline P1 & $30 \times 125$ & 4526,00 & 769 & 31 & 8 & 130 & 1,21 \\
\hline P2 & $30 \times 125$ & 7372,00 & 58 & 276 & 46 & 15 & 1,97 \\
\hline P3 & $30 \times 125$ & 6184,00 & 70 & 280 & 51 & 28 & 1,65 \\
\hline P4 & $30 \times 130$ & 5449,00 & 66 & 343 & 61 & 19 & 1,40 \\
\hline P5 & $30 \times 125$ & 7760,00 & 59 & 302 & 80 & 14 & 2,07 \\
\hline P6 & $30 \times 120$ & 6814,00 & 58 & 239 & 46 & 18 & 1,89 \\
\hline P7 & $30 \times 125$ & 4501,00 & 770 & 29 & 8 & 132 & 1,20 \\
\hline P8 & $30 \times 125$ & 7284,00 & 59 & 254 & 50 & 15 & 1,94 \\
\hline P9 & $30 \times 125$ & 6132,00 & 68 & 295 & 80 & 26 & 1,64 \\
\hline P10 & $25 \times 65$ & 2521,00 & 124 & 7 & 3 & 49 & 1,55 \\
\hline P11 & $25 \times 65$ & 2549,00 & 112 & 7 & 3 & 34 & 1,57 \\
\hline P14 & $25 \times 55$ & 2462,00 & 53 & 39 & 20 & 24 & 1,79 \\
\hline P15 & $25 \times 50$ & 2407,00 & 38 & 21 & 8 & 14 & 1,93 \\
\hline P16 & $30 \times 125$ & 4829,00 & 87 & 253 & 47 & 42 & 1,29 \\
\hline P17 & $30 \times 125$ & 5267,00 & 84 & 247 & 47 & 41 & 1,40 \\
\hline P18 & $30 \times 120$ & 3458,00 & 509 & 22 & 7 & 81 & 0,96 \\
\hline P19 & $30 \times 130$ & 4444,00 & 48 & 290 & 61 & 13 & 1,14 \\
\hline P20 & $30 \times 120$ & 3226,00 & 510 & 28 & 11 & 90 & 0,90 \\
\hline P21 & $20 \times 190$ & 4066,00 & 1497 & 19 & 9 & 223 & 1,07 \\
\hline P22 & $20 \times 190$ & 4626,00 & 1463 & 21 & 11 & 213 & 1,22 \\
\hline
\end{tabular}

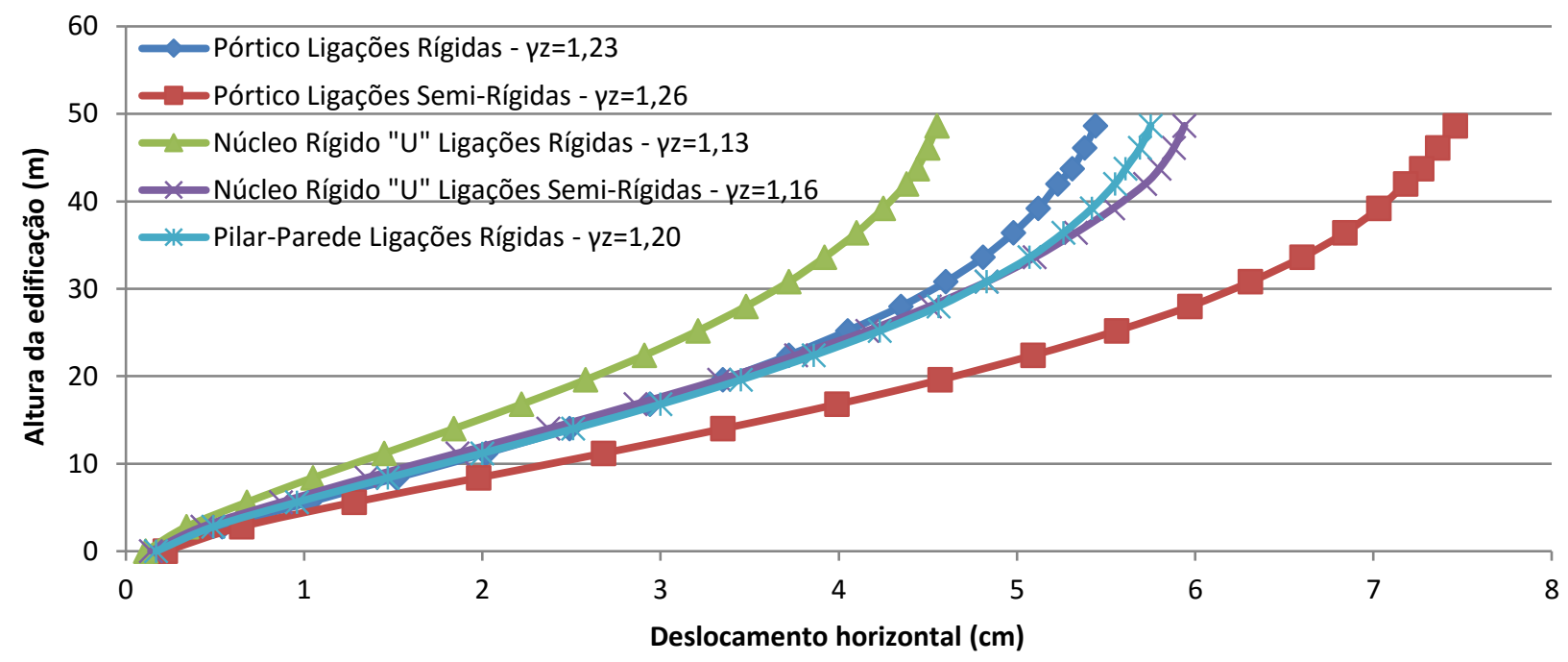

FIGURA 9: Deslocamento Horizontal - Modelos 1,2,3,4,5.

FONTE: Autor (2016).

\subsubsection{Modelo 6}

Por fim, no último modelo, foram consideradas ligações semi-rígidas com $15 \%$ de redução na rigidez entre pilares e vigas. As dimensões dos elementos, da mesma forma que nos exemplos anteriores, foram mantidas iguais, avaliando-se então a influência da rigidez da ligação.
Os valores referentes aos deslocamentos horizontais na análise de primeira e segunda ordem no topo do edifício, bem como a variação do deslocamento no topo da edificação devido as ações característica nas duas direções para o sistema em pilar parede - ligações semi-rígidas estão apresentados na Tabela 11. 
TABELA 11: Deslocamentos horizontais devido a ação do vento no topo do edifício - pilar parede - ligações semi-rígidas.

\begin{tabular}{|c|c|c|c|c|}
\hline Verificações & $0^{\circ}$ & $180^{\circ}$ & $90^{\circ}$ & $270^{\circ}$ \\
\hline Altura total da edificação (cm) & \multicolumn{4}{|c|}{$5.145,00$} \\
\hline Deslocamento limite $(\mathrm{cm})$ & \multicolumn{4}{|c|}{3,03} \\
\hline Deslocamento horizontal Médios 1a ordem $(\mathrm{cm})$ & 2,7 & $-2,7$ & 6,49 & $-6,49$ \\
\hline$\gamma_{\mathrm{f} 2}$ & 0,3 & 0,3 & 0,3 & 0,3 \\
\hline Deslocamento combinações frequentes $(\mathrm{cm})$ & 0,81 & $-0,81$ & 1,95 & $-1,95$ \\
\hline Deslocamento horizontal Médios $1^{\mathrm{a}}$ ordem $+2^{\mathrm{a}}$ ordem $(\mathrm{cm})$ & 3,08 & $-3,08$ & 7,76 & $-7,76$ \\
\hline Variação do Deslocamento no topo da edificação (\%) & 14,15 & 14,15 & 19,54 & 19,54 \\
\hline
\end{tabular}

Através da planta de carga gerada pelo Software EBERICK representada pela Tabela 12, pode-se avaliar os esforços solicitantes gerados na fundação para o sistema de contraventamento com pilar parede - ligações semi-rígidas.

Analogamente ao sistema em pórtico, comparando o modelo 5 e 6, percebe-se que, ao flexibilizar as ligações por meio de ligações $s$ emi-rígidas, há uma perda da rigidez do sistema, evidenciado pelo aumento no valor do $\gamma_{z}$ que passa a ser (1,23), e nos deslocamentos horizontais conforme o gráfico da Figura 11, assim como os esforços na fundação demonstrados na Tabela 12. Embora o consumo de aço e concreto da estrutura pouco sofreu alteração em todos os modelos estudados, pois não houve alterações significativas nas seções transversais dos elementos estruturais conforme pode ser verificado na Tabela 13, o aumento dos momentos nas fundações, bem como as forças horizontais ao comparar as Tabelas 10 e 12, também representará em um acréscimo no custo para a fundação.

TABELA 12: Sistema em pilar parede - Esforços solicitantes de cálculo em pilares com ligações semi-rígidas.

\begin{tabular}{|c|c|c|c|c|c|c|c|}
\hline Nome & Seção (cm) & Carga Máx. (kN) & $\mathrm{Mx}$ (kN.m) & My (kN.m) & Fx (kN) & Fy (kN) & oméd $\left(\mathrm{kN} / \mathrm{cm}^{2}\right)$ \\
\hline $\mathbf{P 1}$ & $30 \times 125$ & 4517,00 & 866 & 31 & 9 & 128 & 1,20 \\
\hline P2 & $30 \times 125$ & 7441,00 & 63 & 302 & 44 & 15 & 1,98 \\
\hline P3 & $30 \times 125$ & 6283,00 & 78 & 306 & 50 & 31 & 1,68 \\
\hline P4 & $30 \times 130$ & 5458,00 & 74 & 364 & 58 & 21 & 1,40 \\
\hline P5 & $30 \times 125$ & 7795,00 & 65 & 329 & 82 & 14 & 2,08 \\
\hline P6 & $30 \times 120$ & 6862,00 & 65 & 256 & 46 & 20 & 1,91 \\
\hline P7 & $30 \times 125$ & 4454,00 & 866 & 30 & 8 & 130 & 1,19 \\
\hline P8 & $30 \times 125$ & 7260,00 & 65 & 277 & 49 & 16 & 1,94 \\
\hline P9 & $30 \times 125$ & 6134,00 & 74 & 320 & 80 & 27 & 1,64 \\
\hline P10 & $25 \times 65$ & 2621,00 & 139 & 8 & 3 & 52 & 1,61 \\
\hline P11 & $25 \times 65$ & 2693,00 & 124 & 8 & 3 & 35 & 1,66 \\
\hline P14 & $25 \times 55$ & 2640,00 & 60 & 42 & 21 & 26 & 1,92 \\
\hline P15 & $25 \times 50$ & 2607,00 & 41 & 23 & 9 & 14 & 2,09 \\
\hline P16 & $30 \times 125$ & 4696,00 & 93 & 275 & 46 & 43 & 1,25 \\
\hline P17 & $30 \times 125$ & 5056,00 & 89 & 270 & 45 & 43 & 1,35 \\
\hline P18 & $30 \times 120$ & 3456,00 & 555 & 24 & 8 & 75 & 0,96 \\
\hline P19 & $30 \times 130$ & 4409,00 & 53 & 315 & 75 & 25 & 1,13 \\
\hline P20 & $30 \times 120$ & 3218,00 & 558 & 29 & 20 & 110 & 0,89 \\
\hline P21 & $20 \times 190$ & 3970,00 & 1698 & 19 & 15 & 240 & 1,04 \\
\hline P22 & $20 \times 190$ & 4453,00 & 1634 & 21 & 22 & 224 & 1,17 \\
\hline
\end{tabular}




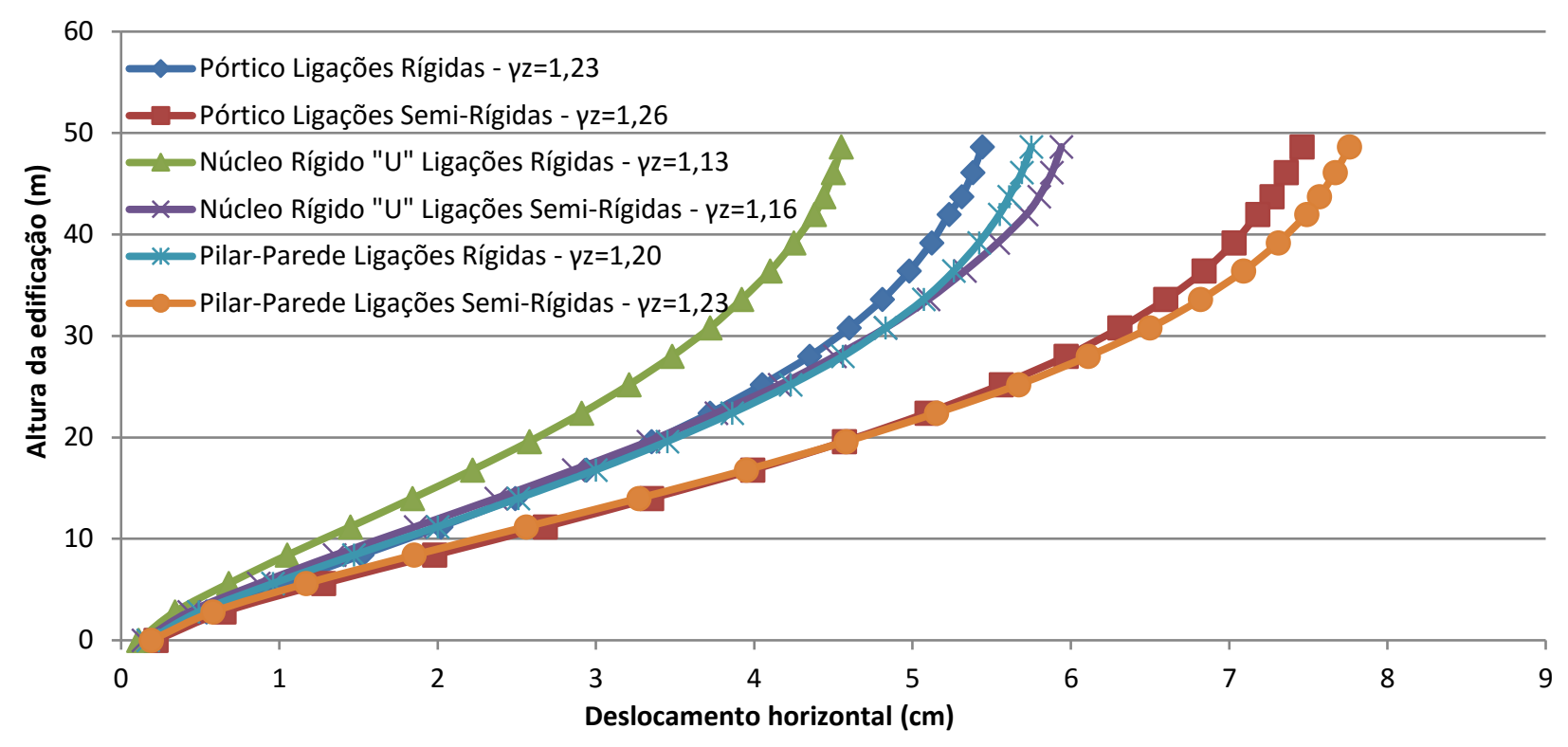

FIGURA 10: Deslocamento Horizontal - Modelos 1,2,3,4,5,6. FONTE: Autor (2016).

\begin{tabular}{ccccc} 
& \multicolumn{2}{c}{ TABELA 13: Resumo Geral dos Modelos em Estudo. } \\
\hline Modelo & $\gamma_{\mathbf{z}}$ & $\begin{array}{c}\text { Deslc. Horiz. Cobertura } \\
(\mathbf{c m})\end{array}$ & $\begin{array}{c}\text { Volume de Concreto } \\
\left(\mathbf{m}^{\mathbf{3}}\right)\end{array}$ & $\begin{array}{c}\text { Peso de Aço } \\
(\mathbf{K g})\end{array}$ \\
\hline Pórtico Ligações Rígidas & 1,23 & 5,45 & 2035,00 & $120.211,70$ \\
\hline Pórtico Ligações Semi-Rígidas & 1,26 & 7,46 & 2035,00 & $121.965,40$ \\
\hline Núcleo "U" Ligações Rígidas & 1,13 & 4,55 & 2065,20 & $119.722,00$ \\
\hline Núcleo "U" Ligações Semi-Rígidas & 1,16 & 5,94 & 2065,20 & $120.814,00$ \\
\hline Pilar Parede Ligações Rígidas & 1,20 & 5,75 & 2043,20 & $121.686,30$ \\
\hline Pilar Parede Ligações Semi- & 1,23 & 7,76 & 2043,20 & $122.222,50$ \\
\hline Rígidas & & & & FONTE: Autor (2016).
\end{tabular}

\section{CONCLUSÕES}

O presente artigo mostra que é tecnicamente possível, conceber sistemas de contraventamento para estruturas de aproximadamente 15 pavimentos utilizando tanto a solução por núcleos rígidos em formato " $U$ ", pilaresparede ou a solução em pórticos formados por vigas e pilares.

Com a utilização de nós semi-rígidos nas ligações das vigas para os três diferentes sistemas de contraventamento deixou evidente que, quanto menor for a participação das vigas no contraventamento da estrutura, maiores serão os valores dos parâmetros de instabilidade, deslocamentos e esforços solicitantes, ocasionando em maiores custos não só para as fundações como também para a própria estrutura.
A vantagem pela utilização de núcleos rígidos é que devido a garantia da estabilidade em função de sua elevada rigidez, permite a redução das seções transversais dos demais elementos da superestrutura constituintes da edificação, por mais que no presente trabalho não foram reduzidas as seções transversais dos elementos estruturais gerando uma economia no consumo de aço e concreto. Em contrapartida gera complicações para a execução das fundações tanto sob a ótica construtiva quanto econômica, por conta dos maiores esforços solicitantes (momentos fletores e forças horizontais).

Além disso, a solução por núcleos rígidos tem maiores impactos arquitetônicos devido a sua grande dimensão quando comparados pela solução em pórticos, e ainda, por mais que a estrutura venha 
a ter sistemas combinados por pórticos e núcleos de grande dimensão, os pórticos formados por vigas e pilares apresentam papel significativo na estabilidade global da mesma, sendo comprovado no Modelo 4.

Recomenda-se então, para edifícios de porte baixo a médio nos quais a estabilização da estrutura costuma ser relativamente simples, a adoção de sistemas de contraventamento constituídos exclusivamente por pórticos, utilizando núcleos rígidos ou pilares-parede somente quando a solução por pórticos não atender aos requisitos técnicos de projeto, evitando desta forma maiores custos para as fundações.

Tendo em vista que o uso de pórticos tem mostrado um bom desempenho para a estabilidade global, a solução que parece ser ideal para este projeto é a de constituir o sistema de contraventamento aproveitando toda a capacidade resistente possível dos mesmos e, na medida do necessário, utilizar os menores pilares-parede possíveis, evitando assim a transmissão de esforços de grande magnitude para as fundações. Nesse conceito, os pilares em formato " $U$ " foram transformados em pilares-parede retangulares, alinhados na direção $y$, desprezando os flanges horizontais.

\section{REFERÊNCIAS BIBLIOGRÁFICAS}

ASSOCIAÇÃO BRASILEIRA DE NORMAS TÉCNICAS. NBR 6118: Projeto de estruturas de concreto Procedimento. Rio de Janeiro, 2007.

ASSOCIAÇÃO BRASILEIRA DE NORMAS TÉCNICAS. NBR 6118: Projeto de estruturas de concreto Procedimento. Rio de Janeiro, 2014. NBR 6120: Cargas para o cálculo de estruturas de edificações - Procedimento. Rio de Janeiro, 1980.

NBR 6123: Força devidas ao vento em edificações - Procedimento. Rio de Janeiro, 1988.

FEITOSA, L. A.; ALVES, E. C. Estudo da estabilidade global de edifícios altos com lajes protendidas. Revista IBRACON de Estruturas e Materiais, v. 8, n. 2, p. 196-224, 2015.

PASSOS, V. M., FEITOSA, L. A, ALVES, E. C., AZEVEDO, M. S. Análise da Instabilidade de Edifícios Altos com Lajes Protendidas e Lajes Nervuradas. Anais do 57을 Congresso Brasileiro do Concreto. Espírito Santo, 2015.
COELHO, J. A. Comparação entre os sistemas de contraventamento através de pórticos e pilares-parede. Santa Catarina, 2010. Disponível em: <http://faq.altoqi.com.br/content/406/684/ptbr/compara\%C3\%A7\%C3\%A3o-entre-os-sistemas-decontraventamento-atraves-de-p\%C3\%B3rticos-epilares_parede.html>. Acesso em: 07 maio 2015.

FRANCO, M.; VASCONCELOS, A. C. D.; Avaliação Prática dos Efeitos de 2a ordem em Edifícios Altos. Coloquiumonthe Rio CEB-FIP-ModelCode 90, Rio de Janeiro, 1991.

WORDELL, F. Avaliação da instabilidade global de edifícios altos. 2003. 91 f. Trabalho de Conclusão (Mestrado em Engenharia) - Mestrado Profissionalizante em Engenharia da Escola de Engenharia, Universidade Federal do Rio Grande do Sul, Porto Alegre.

CARVALHO, Roberto Chust; PINHEIRO, Libânio Miranda. Cálculo e Detalhamento de Estruturas Usuais de Concreto Armado. São Paulo: Pini, 2013. v.2. 